\title{
As políticas linguísticas e a questão da tradução de literatura japonesa para a língua inglesa: um projeto político-ideológico estadunidense
}

\author{
Marcionilo Euro Carlos Neto*
}

RESUMO: Neste trabalho abordamos a questão da manipulação literária nas traduções de literatura japonesa para a língua inglesa, destacando a força da tradução como formadora de identidades culturais e representações domésticas nos leitores. Nos termos de Calvet (2007) trazemos também a questão das políticas linguísticas e sua relação com a manipulação literária, pois, assim como constatamos, os EUA usaram da supremacia e poder político da língua inglesa para criar nos leitores de traduções de obras japonesas para o inglês uma visão de um Japão bucólico, aliado dos americanos e não mais uma força belicosa ameaçadora como outrora.

Palavras-chave: tradução; literatura japonesa; língua inglesa; política linguística; manipulação literária.

\begin{abstract}
In this paper, we address the issue of literary manipulation in Japanese literature translations into English language, highlighting the power of translation as a form to create in readers' cultural identities and domestic representations. We also bring the question of linguistic policies and their relation to literary manipulation, according to Calvet (2007), because, as we have seen, the USA used English language supremacy and political power in order to create in the readers of Japanese translated works a vision of a bucolic and friendly Japan, allied with the Americans and, no longer, a threatening force as it was before.
\end{abstract}

Key-words: translation; Japanese literature; English language; linguistic policy; literary manipulation.

\section{Introdução}

No presente trabalho ${ }^{1}$, apresentaremos as principais obras japonesas traduzidas para a língua inglesa dos Estados Unidos da América, abordando a questão do poder da prática tradutória como formadora de identidades culturais e criadora de representações domésticas no público leitor. Para isso, lançaremos mão das seguintes obras: As políticas linguísticas, de Louis-Jean Calvet (2007), "Política e planificação linguística: conceitos, terminologias e intervenções no Brasil", escrito por Mônica Maria Guimarães Savedra e Xoán Carlos Lagares (2012), Escândalos da tradução: por uma ética da diferença, de Lawrence Venuti (2002 [1998]); além de outras obras que mencionaremos no decorrer deste trabalho.

\section{Políticas linguísticas e a tradução literária}

\footnotetext{
* Doutorando em Estudos de Linguagem pela Universidade Federal Fluminense.

${ }^{1}$ Esse artigo é uma ampliação do capítulo 2 de minha monografia intitulada "As traduções de Kokoro, de Natsume Soseki, para as línguas inglesa e portuguesa" apresentada ao Departamento de Letras Estrangeiras Modernas da Universidade Federal de Juiz de Fora como requisito obrigatório para a conclusão do curso de Bacharelado em Tradução, concluído em fevereiro de 2014.
} 
Atualmente o termo política linguística tem ganhado um espaço considerável em discussões importantes sobre as línguas no mundo. Segundo Savedra e Lagares (2012, p. 11) "o uso dos termos política e planificação linguística é recente, utilizados na literatura da área de sociolinguística no final da década de 50 e início da década de 60 , para dar conta de estudos desenvolvidos em situações linguísticas de contato".

Compreendemos que a preocupação em estudar as línguas em contato e, ao mesmo tempo, entender as políticas linguísticas envolvidas nesse processo, entram em cena nos estudos relacionados às línguas como um campo importante a ser investigado: uma ciência interessada nos agentes sociais e na ação de suas forças.

Calvet (2007, p. 36), na obra As políticas linguísticas, destaca que "na política linguística há também política e que as intervenções na língua ou nas línguas têm um caráter eminentemente social e político". Essa afirmação nos leva a pensar no poder das línguas como um instrumento para fins políticos específicos. Com essa afirmação, podemos relacionar a tradução como um meio de usar a língua alvo para a promoção de ideologias diversas - seus fatores positivos são inegáveis: promover a cultura estrangeira, incrementar o cânone da literatura nacional, trazer o diferente como algo importante para o espelhamento e afirmação da cultura local. Porém, como a história elucida em inúmeros exemplos, a tradução foi e é uma arma apropriada para a criação de representações domésticas intrinsecamente relacionadas às ideologias políticas.

Discutiremos neste trabalho o uso do inglês como língua global, criando representações domésticas através da tradução de literatura japonesa de acordo com um projeto ideológico estadunidense ambicioso de transformação da visão mundial de um Japão belicoso a um país extremamente exótico e bucólico, culminando nos propósitos desejados politicamente pelos Estados Unidos, construindo uma nova imagem do país nipônico como um aliado frente à Guerra Fria e não mais um inimigo da Segunda Guerra Mundial. Também destacaremos a importância de uma língua com status de poder como o inglês para a promoção de outras culturas através das traduções indiretas, possibilitadas pelo poder político-econômico adquirido ao longo da história.

A língua inglesa possui um lugar de importância se comparada com outras línguas no mundo: o seu status de língua global, construído ao longo da história, a equipou com o que era necessário para torná-la uma língua utilizada praticamente ao redor do mundo todo. David Crystal (2003[1997], p. 2) em English as a global language destaca:

Claro que o inglês é uma língua global, (...) você o ouve na televisão falado por políticos de todo o mundo. Enquanto viaja, você vê sinais e avisos em inglês. Quando você entra em um hotel ou restaurante em uma cidade estrangeira, eles vão entender inglês, e haverá um menu em inglês. ${ }^{2}$

Essa importância denotada à língua inglesa foi essencial para que os Estados Unidos desenvolvessem um projeto tradutório que usaria esse status global do inglês como um meio de divulgação de traduções de literatura japonesa de acordo com seu projeto ideológico pretendido. O que analisamos aqui neste trabalho é uma política que usa o poder e o status de uma língua como meio de alcançar objetivos específicos. Crystal (2003[1997], p. 9) salienta que "uma língua tradicionalmente se torna uma língua internacional por um motivo principal: o poder de seu povo - especialmente o

\footnotetext{
${ }^{2}$ Minha tradução. Texto original: Of course, English is a global language, they would say. You hear it on television spoken by politicians from all over the world. Wherever you travel, you see English signs and advertisements. Wherever you enter a hotel or restaurant in a foreign city, they will understand English, and there will be an English menu (2003[1997]: 2).
} 
poder político e militar desse povo". ${ }^{3} \mathrm{Na}$ maioria dos trabalhos sobre políticas linguísticas quase sempre encontraremos algo relacionado com a afirmação de Crystal, pois, o poder político de uma língua está diretamente relacionado ao seu status em relação às línguas consideradas minoritárias. Claro que na história da língua inglesa, encontraremos, provavelmente, épocas em que essa língua não possuía o mesmo poder que possui atualmente.

Os americanos conheciam claramente o poder político-econômico de sua língua e com isso, ao longo da história, usaram esse fator para lograrem projetos audaciosos, trazendo numerosas vantagens para seu país. Até mesmo no Brasil, houve um projeto ideológico de tradução promovido pelos Estados Unidos que propagou ideais capitalistas em uma época em que as ideias socialistas ganhavam força no âmbito nacional: o poder político da língua inglesa incentivou traduções de obras de literatura que criticavam o socialismo e introduziam o ideário capitalista nos leitores. Maria Clara Castellões de Oliveira em seu artigo "Entrelaçamento de tradução e história no contexto brasileiro" (2006) enfatiza o laço formado entre tradução e história com foco no contexto brasileiro nas décadas de 30, 40, 60 e 70, destacando a ideologia capitalista americana como fator manipulador das traduções no contexto brasileiro nessas épocas. Segundo Castellões (2006, p. 168) entre 30 e 40 “(...) o inglês, a partir do boom editorial então ocorrido, assumiu o status de língua de cultura, devido em grande parte ao considerável volume de traduções de textos literários escritos nessa língua", e entre 60 e 70 "a censura da ditadura militar, instaurada em 1964, arrefeceu o vigor das vozes dos intelectuais brasileiros e transformou a tradução em instrumento de veiculação de posturas ideológicas". Castelões (2006, p. 175) conclui que

A história nos mostra a força da presença norte-americana nos rumos políticos e econômicos tomados pelo país a partir do final da década de 30 do século XX, além de desvelar o quanto a ideologia que conduziu ao golpe militar de 1964 e o sustentou foi fundamentada em preceitos econômicos, políticos e ideológicos provenientes dos EUA.

Com o que foi apresentado acima, entendemos como a força política da língua inglesa permitiu que os Estados Unidos usassem a tradução como meio de divulgar suas ideologias e de semeá-las dentro de outras culturas. Nosso foco é elucidar de que maneira o projeto político-ideológico estadunidense, pós Segunda Guerra Mundial, manipulou a escolha das obras de literatura japonesa a serem traduzidas em território americano e, ao mesmo tempo, em outros lugares do mundo, já que a força da língua inglesa como língua global a fez ser utilizada como língua de tradução indireta por outros países.

\section{A tradução de literatura japonesa para a língua inglesa: um projeto político- ideológico}

Segundo Venuti, em Escândalos da tradução: por uma ética da diferença (2002 [1998]), foi nas décadas de 50 e 60 do século XX que a literatura japonesa começou a ter seu boom de traduções para a língua inglesa nos Estados Unidos. Contudo, essas traduções eram muito seletivas, não abrangendo muitos autores de literatura japonesa que, atualmente, são considerados importantes.

Um desses autores importantes é Natsume Soseki que está entre um dos autores japoneses mais traduzidos para a língua inglesa na atualidade: obras como Kokoro e

\footnotetext{
${ }^{3}$ Minha tradução. Texto original "A language has traditionally become an international language for one chief reason: the power of its people - especially their political and military power" (2003[1997]: 9).
} 
Kusamakura, traduzidas por Meredith McKinney, Botchan, traduzida por J. Cohn, e Wagahai neko de aru (I am a cat), traduzida por Aiko Ito e Graeme Wilson, são bem conhecidas entre os leitores de língua inglesa. Um dos fatores responsáveis pelo crescimento do acesso a obras japonesas para a língua inglesa são programas desenvolvidos por fundações como a Japan Foundation (Fundação Japão), que promovem concursos e cursos sobre tradução de literatura japonesa para o inglês. Uma das entidades vinculadas a essa fundação é o Japanese Literature Publishing and Promotion Center (Centro de Publicação e Promoção da Literatura Japonesa) ${ }^{4}$, no qual são desenvolvidos projetos que permitem o acesso a informação sobre tradução e a publicações de língua japonesa; é oferecido apoio a tradutores do japonês para o inglês; são organizados seminários sobre literatura japonesa e promovidas atividades de intercâmbio de informações entre escritores e de divulgação de traduções de obras japonesas para a língua inglesa. Há também programas específicos em diferentes países. $\mathrm{Na}$ Inglaterra, por exemplo, há um projeto da Fundação Japão que treina tradutores especificamente para a tradução de literatura japonesa para o inglês. Cabe destacar que, a referida fundação também se preocupa em divulgar a língua japonesa ao redor do mundo: uma das políticas adotada pela Japan Foundation preocupa-se em promover o ensino da língua japonesa em diversos países.

Percebemos que o governo japonês se preocupou e se preocupa em divulgar a literatura japonesa através de traduções para a língua inglesa. Isso se deve, provavelmente, ao fato de que o inglês, língua falada praticamente no mundo todo, pode ajudar no acesso à literatura japonesa e, assim, divulgar cada vez mais a cultura nipônica para diferentes países. André Lefevere (1992) em Translation, rewriting, and the manipulation of literary fame (Tradução, reescritura e a manipulação da fama literária), discorre sobre a questão de patronagem, ou seja, um sistema que, segundo ele, pode ser controlado por grupos, pessoas, instituições, governos etc. $\mathrm{O}$ autor diz que:

A patronagem está geralmente mais interessada na ideologia da literatura do que na sua poética, e poderia ser dito que o patrono "delega autoridade" ao profissional onde a poética está relacionada.

A patronagem pode ser exercida por pessoas [...], e também por grupos de pessoas, um grupo religioso, um partido político, uma classe social, uma corte real, editores, e, por último, mas não menos importante, a mídia, jornais, revistas e grandes empresas de televisão. Os patronos tentam regular a relação entre o sistema literário e outros sistemas que, juntos, criam uma sociedade, uma cultura (LEFEVERE, 1992, p. 15). ${ }^{5}$

O que o governo japonês fez ao longo dos anos e ainda faz ao promover as traduções de sua literatura é, de certa forma, uma maneira de contribuir para a criação de sistemas de literatura japonesa traduzida dentro de determinadas culturas, de acordo com seu projeto político-ideológico.

\footnotetext{
${ }^{4}$ Minha tradução.

${ }^{5}$ Minha tradução.Texto original: "Patronage is usually more interested in the ideology of literature than in its poetic, and it could be said that the patron "delegates authority" to the professional where poetics is concerned.

Patronage can be exerted by persons, [...] and also by groups of persons, a religious body, a political party, a social class, a royal court, publishers, and, last but not least, the media, both newspapers and magazines and larger television corporations. Patrons try to regulate the relationship between the literary system and the other systems, which, together, make up a society, a culture" (LEFEVERE, 1992: 15). As demais citações desse autor, também serão traduzidas por mim.
} 
As traduções de obras japonesas para a língua inglesa são bastante numerosas. A página da Fundação Japão (http://www.jpf.go.jp/e/db/) ${ }^{6}$ fornece dados bem completos sobre traduções de textos de literatura japonesa para as mais diversas línguas existentes. As traduções para a língua inglesa começaram a ser realizadas apenas nos anos 1930, mais precisamente em 1935, não tendo se estendido, em anos anteriores à Segunda Guerra Mundial, para além de 1936. De acordo com a tabela da Fundação Japão, fizemos o gráfico a seguir com as traduções de literatura japonesa para a língua inglesa publicadas, então, entre 1935 e 1936. O gráfico aponta a enorme prevalência de traduções em 1936:

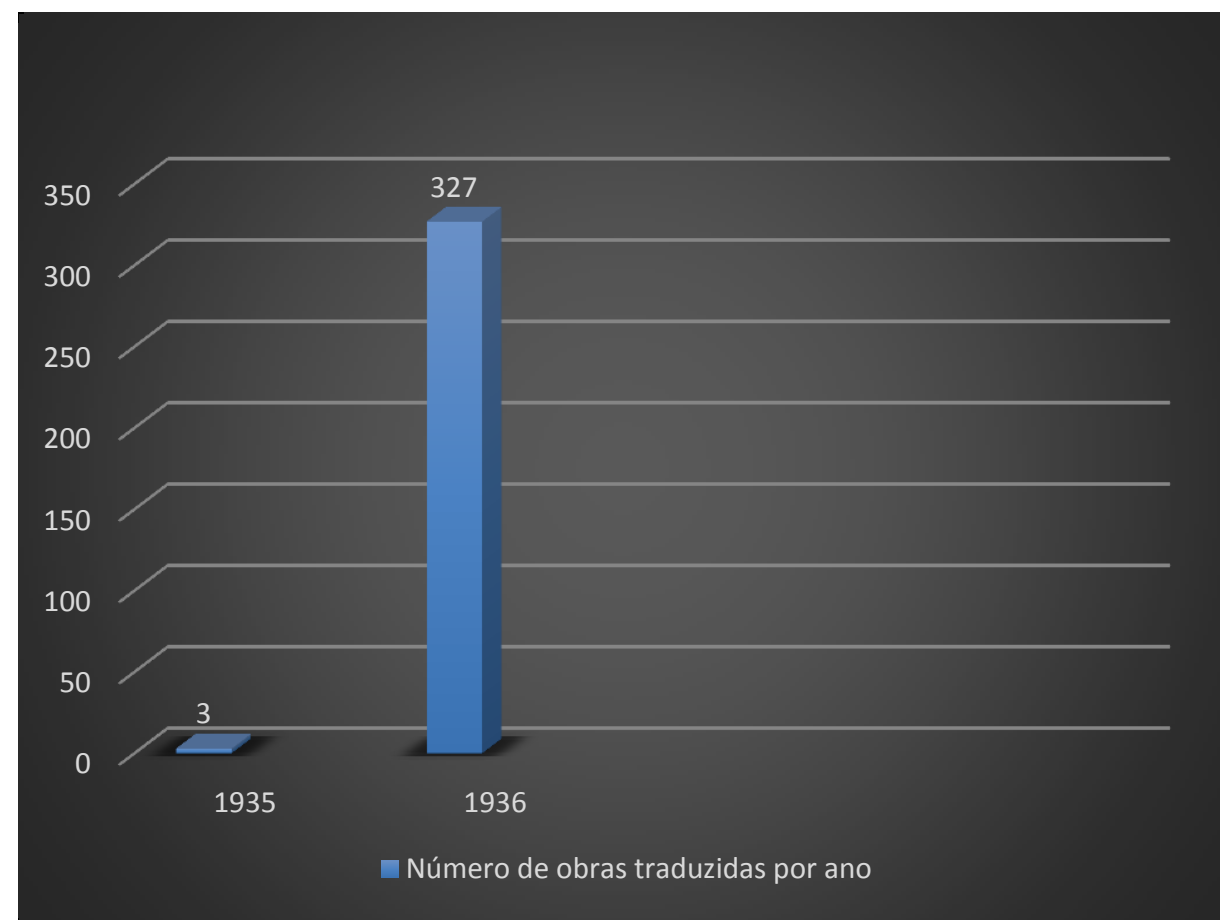

Gráfico 1: Literatura japonesa traduzida para o inglês em 1935 e 1936 de acordo com dados da Fundação Japão disponíveis em http://www.jpf.go.jp/e/db/. ${ }^{7}$

Poucas obras foram traduzidas no ano de 1935, tais como Nyoninaishi - Tojin Okichi monogatari (The story of Chink Okichi), de Yamamoto Yuzo, Seimei no kanmuri (The crown of life) e Sakazaki Dewa no kami (Sakazaki, Lord Dewa), do mesmo autor, totalizando 0,9\% das obras traduzidas nos anos de 1935 e 1936. Já em 1936, observamos um total de 327 obras traduzidas representando 99,1\% das traduções no período citado anteriormente.

No período da Segunda Guerra Mundial (1939-1945), apenas uma tradução foi realizada para a língua inglesa: a obra 5 Haiku, de Kato Shuson, traduzida em 1942. Se considerarmos que o Japão, durante a guerra, estava aliado a países que eram contra os Estados Unidos e a Inglaterra, podemos racionar que o número reduzido de traduções durante o conflito ocorreu por esse motivo. Uma vez que o Japão era um inimigo, os EUA e Inglaterra não tinham interesse em que obras de literatura japonesa fossem traduzidas e que, assim, a cultura japonesa fosse promovida.

Já a partir de 1947, dois anos após o final da guerra, a atividade de tradução de obras da literatura japonesa para o inglês foi retomada. $\mathrm{O}$ gráfico abaixo elucida o

\footnotetext{
${ }_{7}^{6}$ Acessado em 11 de jan. 2014.

${ }^{7}$ Todos os gráficos desse trabalho foram criados de acordo com dados coletados no site da Fundação Japão disponíveis em http://www.jpf.go.jp/e/db/, acessados em 11 de jan. 2014.
} 
número de traduções por ano, entre 1947 a 1950 e nos dá uma ideia do crescimento ou queda das traduções de literatura japonesa para a língua inglesa no período supracitado:

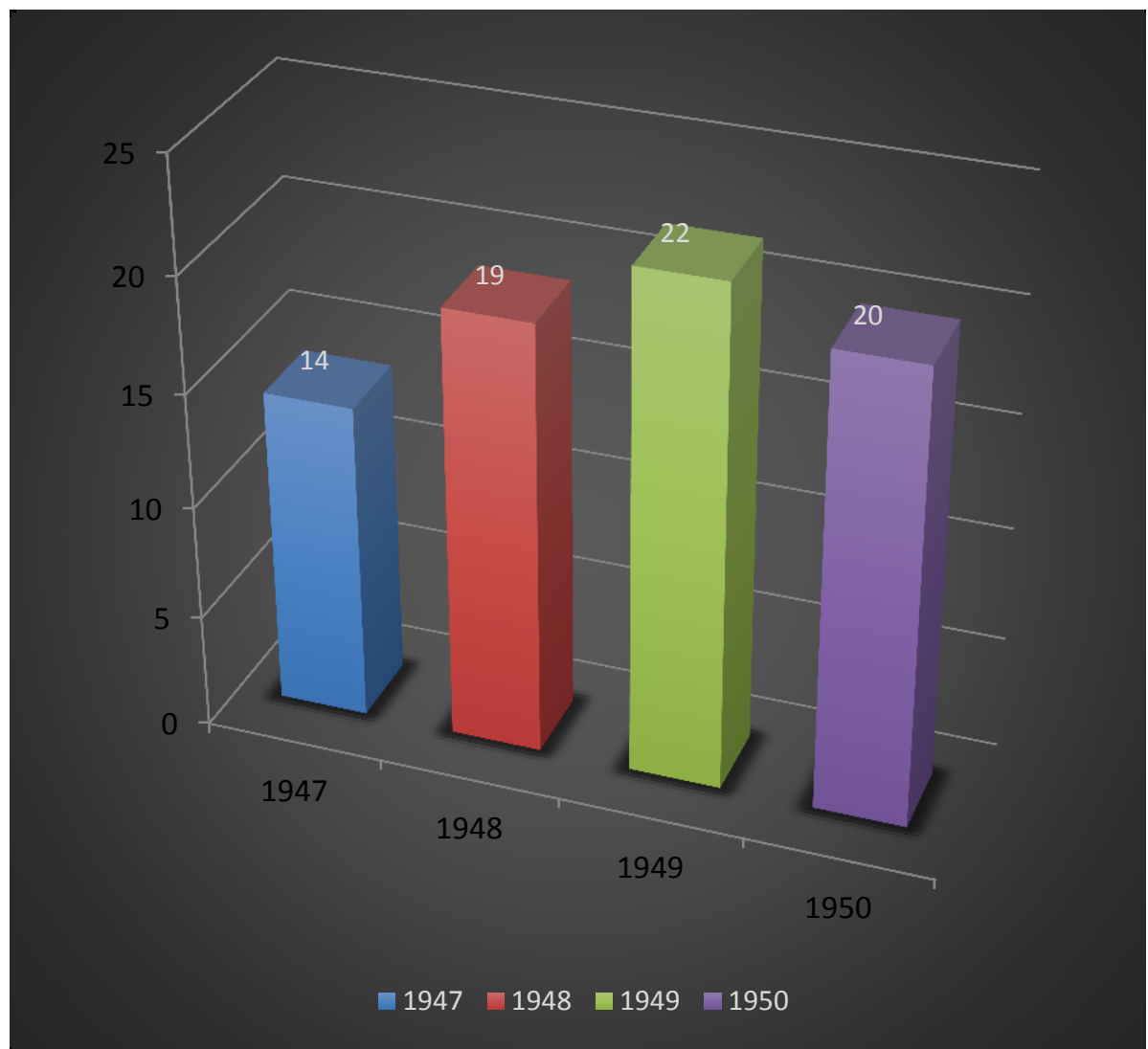

Gráfico 2 - Número de obras de literatura japonesa traduzidas entre 1947 e 1950 de acordo com dados da Fundação Japão disponíveis em http://www.jpf.go.jp/e/db/.

Segundo o gráfico 2, notamos que, a partir de 1947, as traduções de obras de literatura japonesa para o inglês tiveram um crescimento considerável em relação à reduzida produção ocorrida dois anos antes e um ano depois da Segunda Guerra Mundial. Segundo o gráfico, em 1950 houve uma queda no número de traduções realizadas $(26,6 \%)$, mas em 1947(18,6\%), $1948(25,3 \%)$ e $1949(29,3 \%)$ o volume de obras traduzidas mostrou-se crescente.

Uma possível explicação para a queda do número de traduções em 1950, ao compararmos com os anos de 1947, 1948 e 1949, seria justamente o fato de que, a partir de então, elas começaram a ser realizadas de acordo com um projeto político-ideológico bastante definido, que selecionava somente as obras de alguns autores, tais como Kawabata Yasunari, Tanizaki Jun'ichiro e Mishima Yukio, para serem traduzidas para o inglês.

Podemos afirmar que o volume de traduções de obras de literatura japonesa para a língua inglesa na década de 1960 é bem elevado, representando um total de 1.738 obras traduzidas nesse período, enquanto na década de 1950 há referências de um número de apenas 20 obras traduzidas. O gráfico seguinte explicita o volume de traduções realizadas em cada um dos anos da década de 60 : 


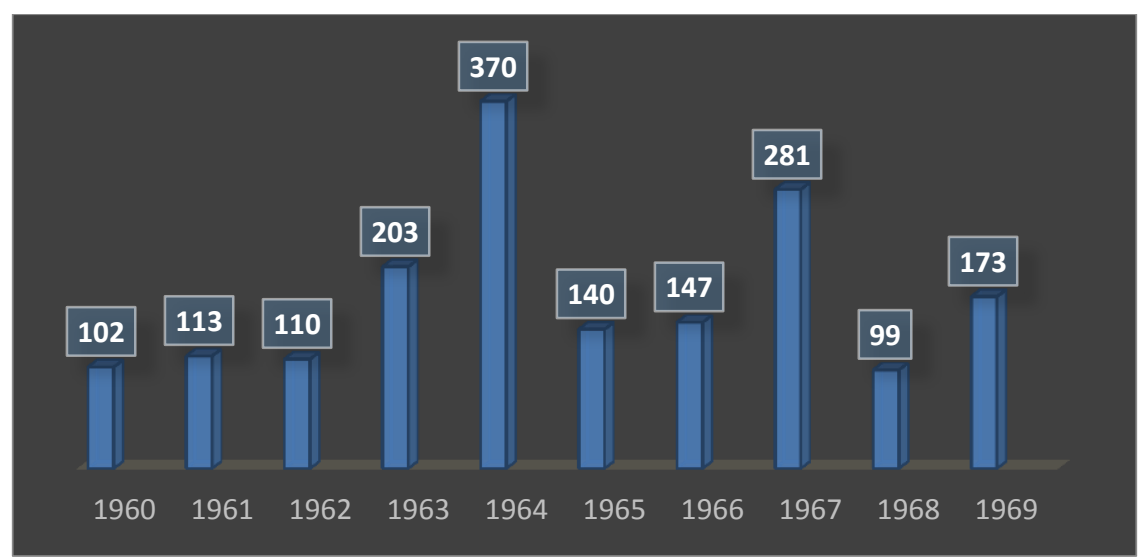

Gráfico 3- Número de obras de literatura japonesa traduzidas entre 1960 e 1969, de acordo com dados da Fundação Japão disponíveis em http://www.jpf.go.jp/e/db/.

De acordo com o gráfico 3, é possível visualisar como o volume de traduções na década de 60 foi bastante grande. Em 1964, particularmente, o número de traduções foi bem elevado, totalizando 370 títulos traduzidos para a língua inglesa $(21,3 \%$ do total de obras traduzidas na referida década). $\mathrm{O}$ ano que apresenta menor número em relação aos demais é 1968, com um total de 99 obras $(5,7 \%)$.

Devemos mencionar também quais os autores foram o mais traduzidos na década de 60, já que essas traduções foram extremamente selecionadas de acordo com projeto político-ideológico estadunidense:

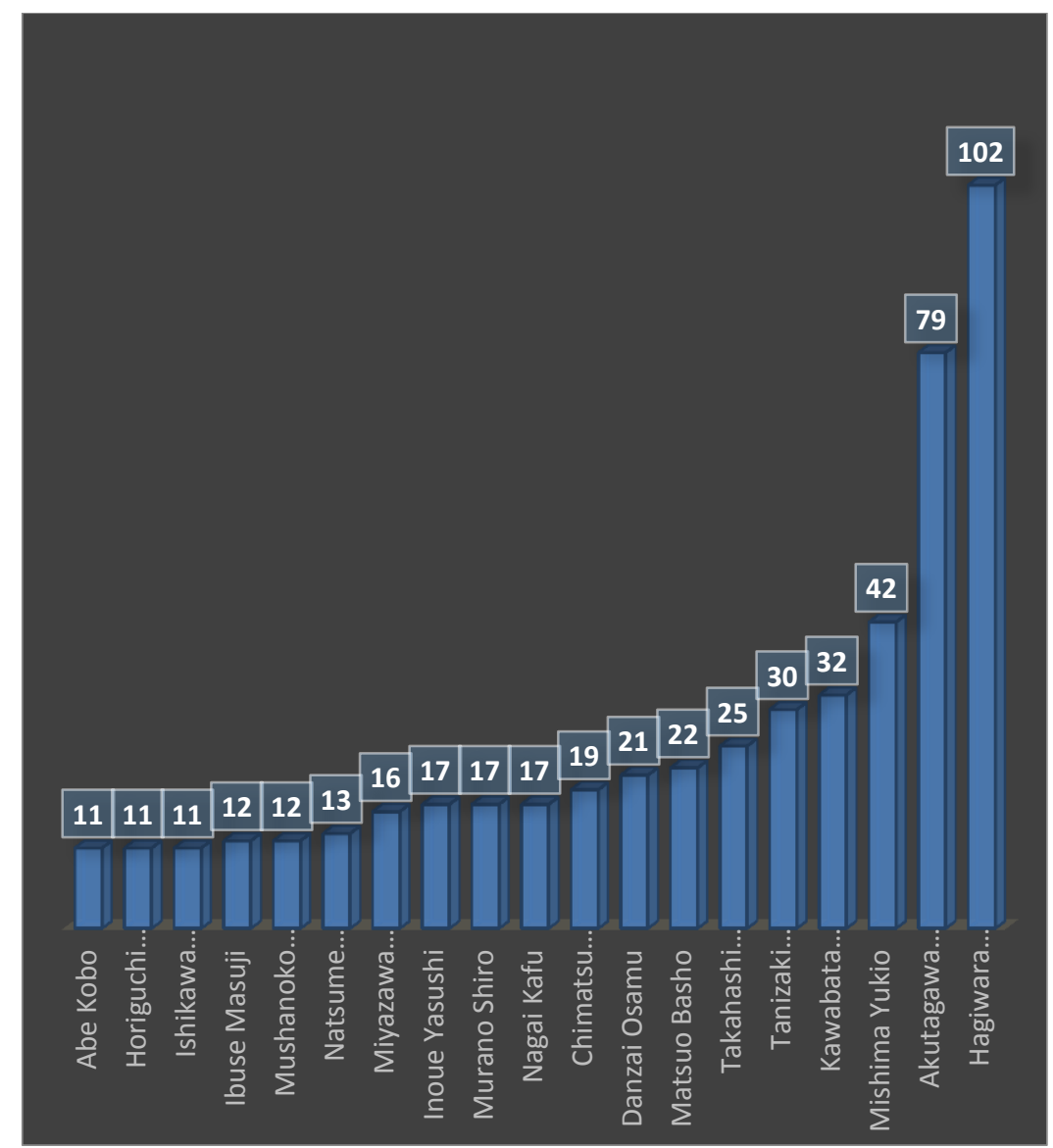

Gráfico 4 - Autores de literatura japonesa mais traduzidos para a língua inglesa na década de 60 de acordo com dados da Fundação Japão disponíveis em http://www.jpf.go.jp/e/db/. 
De acordo com o gráfico acima, podemos afirmar que autores como Hagiwara Sakurato (102), Akutagawa Ryunosuke (79) e Mishima Yukio (42), tiveram grande número de obras traduzidas para o inglês durante a década de 1960, representando, de acordo com o total de títulos traduzidos nesse período (509 obras), respectivamente, $20,03 \%, 15,5 \%$ e $8,2 \%$.

As obras traduzidas para o inglês serviram de ponto de partida para que a literatura nipônica conseguisse penetrar em outras culturas que, até então, desconheciam completamente a literatura produzida no Japão. No Brasil, por exemplo, muitas obras de literatura japonesa que aqui chegaram tiveram o inglês como língua intermediária. A maioria das traduções para o português de obras de Yukio Mishima, por exemplo, foi realizada através de traduções indiretas da língua inglesa.

Venuti, em Escândalos da tradução: por uma ética da diferença (2002 [1998], p. $158),{ }^{8}$ afirma que "um projeto tradutório deve considerar a cultura onde o texto estrangeiro tem sua origem e se dirigir a várias comunidades domésticas". Isso quer dizer que o etnocentrismo deve ser contido a fim de que as particularidades da língua e da cultura do original não sejam apagadas ou obliteradas ao longo do processo tradutório.

O poder da tradução em criar para outras culturas uma imagem da cultura do texto original é muito grande. Lefevere (1992, p. 5), em Translating, rewriting and the manipulation of literary fame (Tradução, reescrita e manipulação da fama literária), discorre sobre esse poder, afirmando que

no passado, como no presente, reescritores criaram imagens de um escritor, de uma obra, de um período, de um gênero e, às vezes, de toda uma literatura. Essas imagens existiram ao lado das realidades com as quais elas competiam, mas as imagens sempre tenderam a alcançar mais pessoas do que as realidades correspondentes e, assim, isso muito certamente acontece hoje".

Segundo Venuti, a própria escolha dos textos que serão traduzidos é uma maneira de manipulação, que se embasa em projetos de formação de identidades culturais interligados a interesses ideológicos, políticos, econômicos etc. Observando textos traduzidos para a língua inglesa dos Estados Unidos após o término da Segunda Guerra Mundial, Venuti notou que essas traduções foram minuciosamente selecionadas de acordo com o projeto estadunidense expansionista, que queria transformar a imagem do Japão de um país de força bélica considerável a um país exótico e aberto ao estrangeiro: "o Japão era representado como uma 'terra exótica e estetizada, puramente estrangeira, um tanto quanto antitética à sua imagem pré-guerra de uma potência belicosa e iminentemente ameaçadora" (FOWLER, 1992, p. 3, grifo de Fowler apud VENUTI, 2002 [1998], p. 139). Essa imagem, segundo Venuti, culminava com o projeto de aliança dos Estados Unidos com o Japão, evitando a expansão russa durante o período da Guerra Fria. Citando Fowler, ele diz que

[...] as esferas estetizadas [nos romances selecionados para a tradução] estabeleceram exatamente a imagem correta do Japão numa época em que o país estava sendo transformado, quase que da noite para o dia, em termos

\footnotetext{
${ }^{8}$ Toda vez que mencionarmos Lawrence Venuti, a referência será a mesma, ou seja, Escândalos da tradução: por uma ética da diferença (2002 [1998]).

${ }^{9}$ Texto original: "In the past, as in the present, rewriters created images of a writer, a work, a period, a genre, sometimes even a whole literature. These images existed side by side with the realities they competed with, but the images always tended to reach more people than corresponding realities did, and they most certainly do so now" (LEFEVERE, 1992: 5).
} 
históricos, de um inimigo mortal durante a Guerra do Pacífico num aliado indispensável durante a época da Guerra Fria (FOWLER, 1992, p. 6 apud VENUTI, 2002 [1998], p. 139-140).

Assim, as obras japonesas traduzidas para o inglês dos EUA entre 1950 e 1960 foram selecionadas dando preferência a poucos autores japoneses, de acordo com o ideal estadunidense de construção da visão dos sujeitos domésticos em relação aos japoneses e seu país.

Venuti afirma que, entre 1970 e 1980, o cânone de tradução de romances japoneses estabelecido nos Estados Unidos não sofreu praticamente nenhuma alteração. Porém, no final da década de 1980, esse cânone começou a mudar significativamente, devido a uma nova geração, que, mais aberta a diferentes temas, se interessava, principalmente, pela influência esmagadora que as culturas ocidentais estabeleceram sobre o Japão.

Essa preocupação a respeito da ocidentalização japonesa despertou interesses que culminaram numa mudança brusca em relação às obras japonesas traduzidas para a língua inglesa. É nesse contexto que autores como Natsume Soseki começam a ganhar espaço dentro de outras culturas, como a estadunidense, sendo mais traduzidos, pois, nesse momento, já satisfazem às expectativas e planos de um novo público leitor mais aberto a outras questões sobre o Japão. Venuti (2002 [1998], p. 141) afirma que

os projetos tradutórios podem produzir uma mudança na representação doméstica de uma cultura estrangeira, não somente quando revisam os cânones das comunidades culturais mais influentes, mas também quando outra comunidade numa situação social diferente produz as traduções e se manifesta sobre elas".

Ainda sobre esse novo momento de traduções de literatura japonesa para a língua inglesa, Venuti acrescenta que os tradutores começam a se preocupar em traduzir autores e textos que foram produzidos num "Japão pós-guerra americanizado" e de certa maneira dão partida a um movimento de mudança do cânone da literatura japonesa traduzida para o inglês formado através de interesses dos EUA, que não mais condiziam com a realidade do novo momento que estavam vivendo. Com isso, o cânone é revisado e começa a se focar num público de leitores menos acadêmico.

Venuti cita a tradução de Kitchen, de Banana Hashimoto (1993), como um dos exemplos mais claros dessa mudança. Kitchen revela um Japão mais ocidentalizado e não mais um país extremamente exótico e estetizado: "as duas partes em Kitchen, uma novela e um conto, representam personagens japoneses jovens e extremamente ocidentalizados, traços que foram repetidamente citados nas resenhas como fontes de fascinação" (2002 [1998], p. 143).

\section{Considerações Finais}

Como afirmado anteriormente, o poder da língua inglesa culminou na divulgação da literatura nipônica além das fronteiras dos países que usam o inglês como língua materna, ao mesmo tempo que criou uma visão doméstica sobre o Japão nos leitores das traduções, de acordo com os ideais estadunidenses. Se observarmos as primeiras traduções de literatura japonesa em países latinos, iremos encontrar com facilidade um número grande de traduções indiretas, ou seja, as obras não eram traduzidas diretamente da língua japonesa e sim de traduções já executadas para outras línguas, como a inglesa. Esse fato pode ser prejudicial à qualidade do texto de chegada, 
uma vez que a tradução indireta tende a ser mais deformadora da letra (cf. BERMAN, 2007 [1985]).

Contudo, o governo japonês com seus projetos de incentivo e apoio a tradutores de língua japonesa está conseguindo aumentar, cada vez mais, o número de traduções diretas de diferentes obras de sua literatura em diversos países. Com isso, o Japão consegue ampliar o leque de autores traduzidos e, ao mesmo tempo, consegue promover as obras de acordo com a ideologia política japonesa, tentando aumentar o acesso a essas obras através das traduções. Porém, o poder político de uma língua como o inglês, ainda permite e continuará dando suporte aos Estados Unidos a divulgar através da língua inglesa obras que façam parte de um projeto político-econômico-ideológico ambicioso, manipulando as traduções que forem condizentes a esse projeto, criando representações domésticas de acordo com os ideais pretendidos.

\section{Referências}

BERMAN, Antoine. A tradução e a letra ou o albergue do longínquo. Trad. MariaHélène Torres et al. Rio de Janeiro: 7Letras/PGET, 2007 [1985].

CALVET, Louis-Jean. As políticas linguísticas. Trad. de Jonas Tenfen, Isabel de Oliveira Duarte e Marcos Bagno et al. Parábola, 2007.

CRYSTAL, David. English as a global language. Cambridge: Cambridge University Press, 2003 [1997].

LEFEVERE, André. Translation, rewriting and the manipulation of literary fame. London: Routledge, 1992.

OLIVEIRA, Maria Clara Castellões de. Entrelaçamento de tradução e história no contexto brasileiro. Revista Ipotesi v. 10, n.1, n.2 p. 167 - 177, jan/jun, jul/dez 2006.

SAVEDRA, Mônica Maria Guimarães \& LAGARES, Xoán Carlos. Política $e$ planificação linguística: conceitos, terminologias e intervenções no Brasil. Revista Gragoatá, EDUFF, vol. 32, 2012

VENUTI, Lawrence. The Translator's Invisibilty: A History of Translation. 2 ed. London, New York: Routledge, 2008 [1995].

. Escândalos da Tradução: por uma ética da diferença. Trad. de Laureano Pelegrin et al. São Paulo: EDUSC, 2002 [1998].

\section{Sites da internet}

Fundação Japão. Disponível em: http://www.jpf.go.jp/e/db/. Acesso em: 11 jan. 2014.

Revista Campo e Cidade. Literatura Japonesa. Disponível em: http://www.campoecidade.com.br/edicao-56/literatura-japonesa/. Acesso em: 25 nov. 2013.

Data de envio: 02-04-2017

Data de aprovação: 02-05-2017

Data de publicação: 10-07-2017 